\title{
Characterization and Modeling Study on Softening and Seepage Behavior of Weakly Cemented Sandy Mudstone after Water Injection
}

\author{
Junting Guo $\mathbb{D}^{1,2}$ Teng Teng $\mathbb{D}^{1,2,3}$ Xiaoyan Zhu $\mathbb{D}^{2}, 2$ Yuming Wang $\mathbb{D}^{2}$ Zhaolong $\mathrm{Li}^{\mathbb{D}}{ }^{2}$ \\ and Yi Tan iD ${ }^{1,4}$ \\ ${ }^{1}$ State Key Laboratory of Water Resource Protection and Utilization in Coal Mining, Beijing 102209, China \\ ${ }^{2}$ School of Energy and Mining Engineering, China University of Mining \& Technology-Beijing, Beijing 100083, China \\ ${ }^{3}$ State Key Laboratory for Geo-Mechanics and Deep Underground Engineering, China University of Mining \& Technology-Beijing, \\ Beijing 100083, China \\ ${ }^{4}$ School of Energy Science and Engineering, Henan Polytechnic University, Jiaozuo 454002, China
}

Correspondence should be addressed to Teng Teng; t.teng@cumtb.edu.cn

Received 11 October 2021; Accepted 15 November 2021; Published 7 December 2021

Academic Editor: Fazhi Yan

Copyright (C) 2021 Junting Guo et al. This is an open access article distributed under the Creative Commons Attribution License, which permits unrestricted use, distribution, and reproduction in any medium, provided the original work is properly cited.

Water injection-induced rock softening and the associated water seepage characteristics are the common and basic problems in underground reservoir construction and the prevention of mine water disaster. In this paper, a series of experimental studies was carried out to investigate these characteristics with the weakly cemented sandy mudstone collected from Shendong Buertai coal mine, China. The characteristics of water softening and the stress-seepage interactions in water-saturated weakly cemented sandy mudstone were directly obtained. Then, a modification method of the constitutive model for rock mass considering the softening effect and a stress-damage-driven model for permeability evolution were established. Research results show that water saturation reduces the tensile strength, compressive strength, and cohesion by $56 \%$ and reduces the elastic modulus by $28 \%$. The hydraulic effects on Poisson's ratio and internal friction angle are negligible. The relationship between the permeability of weakly cemented sandy mudstone with complete compaction deformation is to be divided into three stages of seepage shielding, seepage surge, and seepage recovery. Rock permeability in each stage has a negative exponential relationship with the effective stress. This research provides a theoretical basis for the researches of hydromechanical couplings on weakly cemented sandy mudstone, which is insightful for rock engineering practice.

\section{Introduction}

Shendong coal mining area, spanning three provinces of Shaanxi, Mongolia, and Shanxi, is now the largest mining area of coal mine in China, among which Buertai coal mine is the largest mining area in the world. The host rock of Shendong coal mining area mainly consists of sandstone and sandy mudstone [1-3]. In general, these rocks are weakly cemented and the softening effects under water saturation are significant [4-6]. It is very common for the mas- sive roof hanging in the hard roof condition, especially for massive sandstone and carbonaceous roofs. Water injection and hydraulic fracturing into the main roof can effectively manage the stress and reduce the probability of bursting events. For example, the roof at Buertai coal mine 42108 longwall face was softened and fractured by water injection and fracturing. As a result, the length and magnitude of periodic weighting reduced $18.9 \% \sim 70.6 \%$ and $13.7 \% \sim 19.4 \%$, respectively [7]. On the other hand, it is critical to understand the dynamic stability of underground structure under 
a hydromechanical coupling effect. This is because protection of groundwater has the highest priority at Shendong mining area [8]. In addition, rock engineering associated with tunnels, water conservancy, and underground chambers in western China also encounters varying degrees of water softening and seepage problems. Therefore, it is of great importance to study the hydraulic effects and seepage characteristics of weakly cemented rocks in Shendong coal mining area.

The physical and mechanical properties of weakly cemented rocks in western China can change substantially when saturated. A series of researchers has carried out experiments and mechanism studies on the water softening effect of weakly cemented rocks [9]. Under the coupled hydromechanical conditions, the initial unloading state promotes the nucleation of the secondary cracks at the low internal hydraulic pressures, whereas the nucleation of secondary cracks is inhibited when the hydraulic pressure of the fluid injection is high [10]. It is suggested that retaining a high initial water content in crushed mudstone can maintain its stability of the shear stress. During creep immersion, the increment in the creep-shear displacement increases as the creep-stress ratio increases, and the initial water content decreases. Under the same density, the peak shear strength decreases with an increase in the increment of the creepshear displacement [11]. Experiments of complete stressstrain curves under natural condition and water-saturated condition indicate that the peak strength decreases by $21.6 \%$ and $17.3 \%$, respectively, when test block reacts with water in the elastic and plastic stage, but residual strength decreases by $4.1 \%, 33.8 \%, 9.6 \%$, and $55.9 \%$ during the elastic, plastic, strain-softening, and residual stage under action of water. Overall, the mudstone roofs containing high water absorption capacity minerals make it disintegrate easily and expand strongly; another aspect is that its peak strength and residual strength decrease after reacting with water, which is the instability mechanism of mudstone roofs [12]. Water saturation changes the mesoscopic mechanism of rock spalling through true-triaxial compression tests. The mechanisms of water on rockburst prevention are to reduce residual elastic strain energy, avoid excessive concentration of strain energy, and increase rockburst resistance. The ratio of the far-field maximum principal stress to the uniaxial compressive strength can be used as an index to evaluate the stability of hard-rock tunnels [13]. Liu et al. [14] discussed the influence of saturation on the strength parameters, deformation characteristics, and energy evolution of the mudstone at Badong formation. Based on the findings, they proposed a relationship between mechanical properties, energy evolution, and microcrack development. The results are insightful for the water-bearing weak cemented rock mass in Shendong coal mining area.

The seepage of water in the fractured rock mass results in the change of water content within the rock, which in turn leads to the hydromechanical interactions [15-17]. After water injection, more pores with diameter larger than $10 \mathrm{~nm}$ are formed that would improve the transport capacity of gas in pores [18]. The changes of porosity and permeability are obvious in the carbonate rock after low-salinity water injection, and it is important in the near injection area [19]. Water pressure in pore and seepage flow can macroscopically characterize the seepage situation of the rock formation, and the change of pore pressure generally goes through five stages of the initial constant stage, increase phase, peak fluctuation phase, decay phase, and stable phase [20]. Robert et al. [21] found that during a vertical loading and unloading cycle, hysteresis in flow was observed signifying the importance of stress history on fracture flow. The pore water pressure decreases by increasing the permeability, but the changes in pore water pressure distribution become negligible once the magnitude of permeability is above $1 e^{-8} \mathrm{~m} / \mathrm{s}$ [19]. The permeability evolution in triaxial compression test after the sample failure increases up to two orders of magnitude for mudstone, while the permeability for gypsum does not increase and the final permeability is even lower than the initial permeability due to the different failure modes [22]. Flow properties of fault in mudstone may be able to be estimated from stress condition and a yield criterion of the host rock [23]. Grain size distribution and mineralogical composition control the vertical permeability; the compaction trends of pure quartz and quartz-smectite 15:85 mixtures describe the maximum and minimum boundaries, respectively [24]. For concrete, it is determined that the measurement methods significantly affect the density, porosity, and permeability values. When the size of aggregate and mixture ratios are ignored, the coefficient of constant head permeability tests is found to be $75 \%$ of the coefficient of falling head permeability tests, on average [25]. When the flow is laminar and the Reynolds number is small enough $(<10)$, fluid flow depends on the discontinuity between the pressure in solid and in liquid, and the permeability depends on the porosity and specific surface area of pores and cracks [26].

At present, the coal mining disaster prevention and control and underground space excavation at the Buertai Mine in Shendong mining area have experienced hydromechanical couplings and water seepage problems. However, the systematic research on this issue is still limited. Based on the weakly cemented sandy mudstone in Shendong coal mining area, this paper studies common issues such as water softening effects on rock mechanics and water seepage behaviors through experiments. Such investigations include experiments on rock saturation process, uniaxial compression, triaxial compression, Brazilian splitting, and seepage. The research results can effectively enrich the fundamental theory of rock mechanics and provide guidance for related engineering practice.

\section{Analysis of Rock Saturation Characteristics}

Rock samples used in the test were cored from Buertai coal mine, Shendong mining area, China. The mining seam has a sandy mudstone roof with a depth of about 450 meters, and the density of the sandy mudstone is approximately $2.44 \mathrm{~g} / \mathrm{cm}^{3}$. The coring site can be seen in Figure 1 .

Prior to the test, part of the rock samples was dried under $105^{\circ} \mathrm{C}$ for $24 \mathrm{~h}$ [27]. After natural cooling, they were soaked in water until fully saturated. Because the sandy mudstone is weakly cemented, some samples disintegrated in the saturation process. Figure 2 shows the saturation 


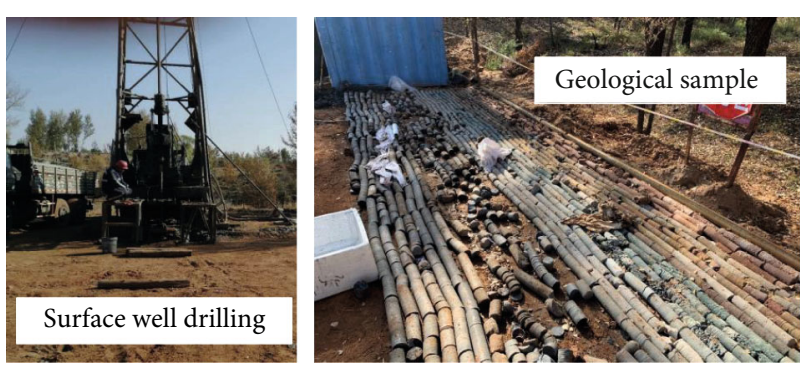

Figure 1: Geological samples at the site.

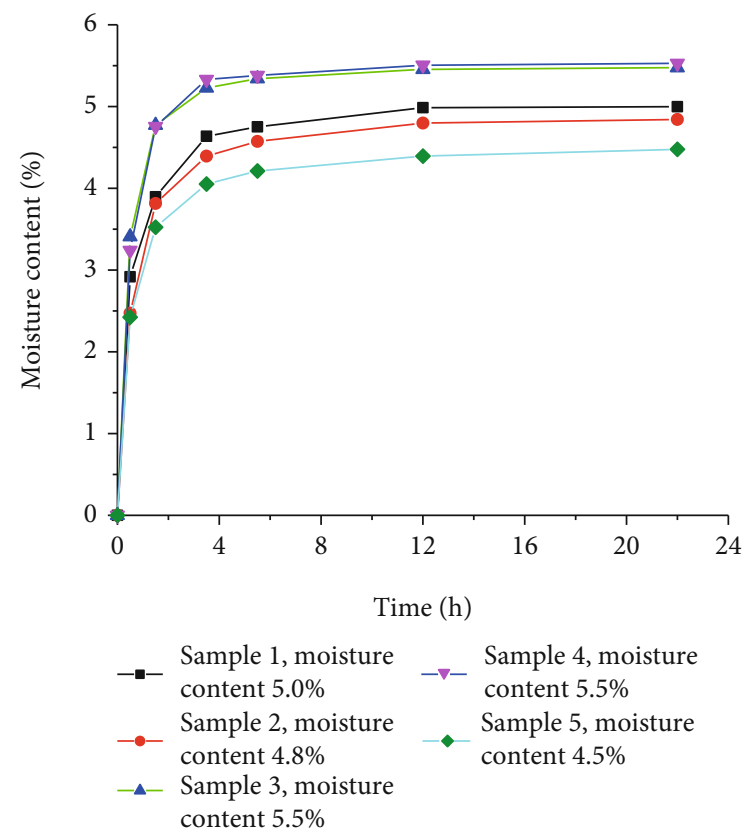

FIgURE 2: Saturation curves of rock samples.

curves of the dry rock samples for the experiment. It can be seen that the saturation rate of the rock sample gradually slows down with time. The saturation process mainly occurred within the first six hours after immersion; and the water content does not change much in the subsequent 18 hours. The saturated sandy mudstone samples used in this experiment are immersed for about 24 hours. In this study, the time effects of water saturation on natural and saturated rock samples are not considered. Based on the results, it is clear that the sandy mudstone used in the test has a natural water content of $1.3 \%$ and an average saturated water content of $5.06 \%$.

\section{Water Softening Effect and Modification of Constitutive Model}

3.1. Laboratory Tests. The collected rock cores are shaping into two kinds of geometries. The first type of rock samples was cut as cylindrical samples with a diameter of about $50 \mathrm{~mm}$ and a height of $100 \mathrm{~mm}$, which were used for compression and permeability tests. The other type was prepared as disc samples with a diameter of about $50 \mathrm{~mm}$ and a height of $25 \mathrm{~mm}$ that were suitable for the Brazilian test. The parallelism of the upper and lower ends and the flatness of the faces were both less than 0.02 .

Figure 3(a) shows a servo-controlled stress-seepage-temperature-chemical (MHTC) coupling system at China University of Mining and Technology-Beijing, which was used to conduct triaxial compression tests and seepage tests on natural and fully saturated rock samples. The experiments are aimed at studying the deformation under various confining pressures. During the test, both axial and confining pressures were displacement controlled at a rate of $0.001 \mathrm{~mm} / \mathrm{s}$. To investigate the influence of in situ formation pressure on the water softening characteristics of rock, the confining pressures were set as $0,4,6$, and $8 \mathrm{MPa}$, respectively, corresponding to the depth that varies from 0 to $1000 \mathrm{~m}$. A MTS Exceed E45 rock mechanics testing system from China University of Mining and Technology-Beijing (see Figure 3(b)) was used to carry out the Brazilian tests on natural and fully saturated rock samples. The axial load is also controlled by changing the displacement at a speed of $0.001 \mathrm{~mm} / \mathrm{s}$.

3.2. Effect of Water Softening on Compressive Characteristics. The compressive properties of natural and saturated sandy mudstones were obtained from uniaxial compressive and triaxial tests. Tests at each confining pressure were repeated three times. Figure 4 shows the evolution of circumferential and axial strains with the deviatoric stress under different confining pressures. By comparing the uniaxial and triaxial compressive stress-strain curves of natural and saturated sandy mudstones, one can find that the compressive strength of fully saturated rock samples is significantly lower than that of natural state rock samples. Thereby, the plastic compaction before the peak strength becomes more obvious for fully saturated rock (A in the figure), whereas the stress failure after the postpeak slows down. In addition, Figure 4 indicates a transition from brittle failure of natural rock to plastic failure of saturated rock (position B). The above analysis indicates that water injection can significantly increase the plasticity of sandy mudstone. The detailed softening effect and quantitative analysis of mechanical parameters will be addressed in Section 3.4.

3.3. Effect of Water Softening on Tensile Characteristics. The Brazilian test was implemented to estimate the tensile strength of the natural and saturated rock samples, and four sets of tests were carried out under each state. Figure 5 shows the force-displacement curves obtained from the Brazilian test. It can be seen from Figure 5 that the failure strength (force) of the rock sample in the natural state is substantially greater than that of the saturated rock sample. In the natural state, the force and deformation of the sandy mudstone prior to the peak are almost elastic. At the same time, the force after the peak tensile strength drops dramatically and the brittle fracturing of the rock is obvious. On the other hand, the force-displacement curve and deformation characteristics of the Brazilian test for the rock sample in fully saturated state are similar to those of uniaxial and triaxial tests, especially the plastic behavior and fluctuated loading after the peak failure. 


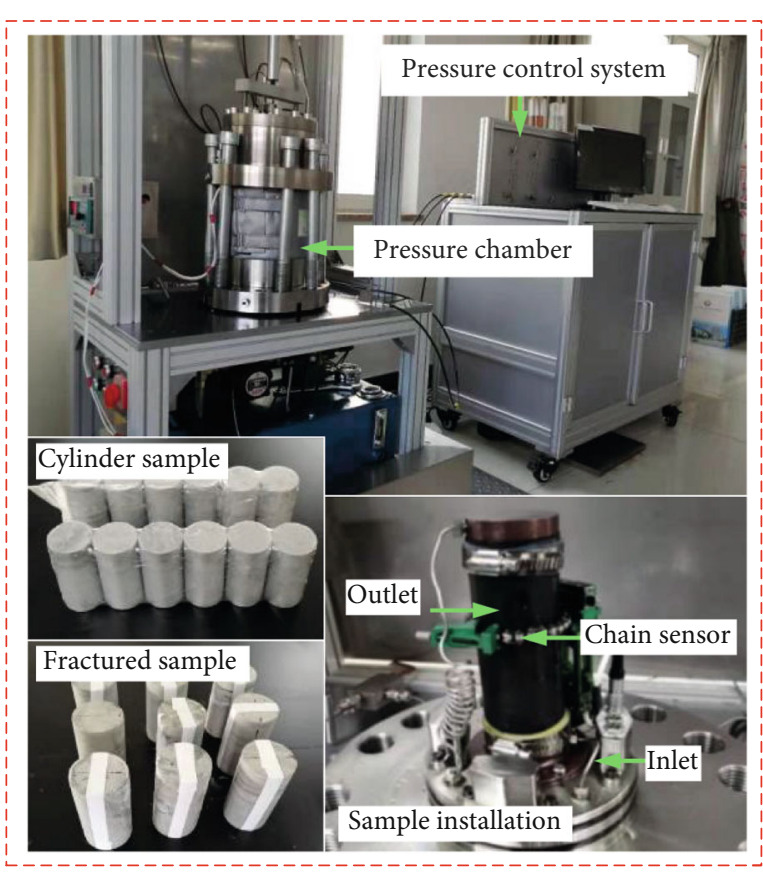

(a) The MHTC servo-control system

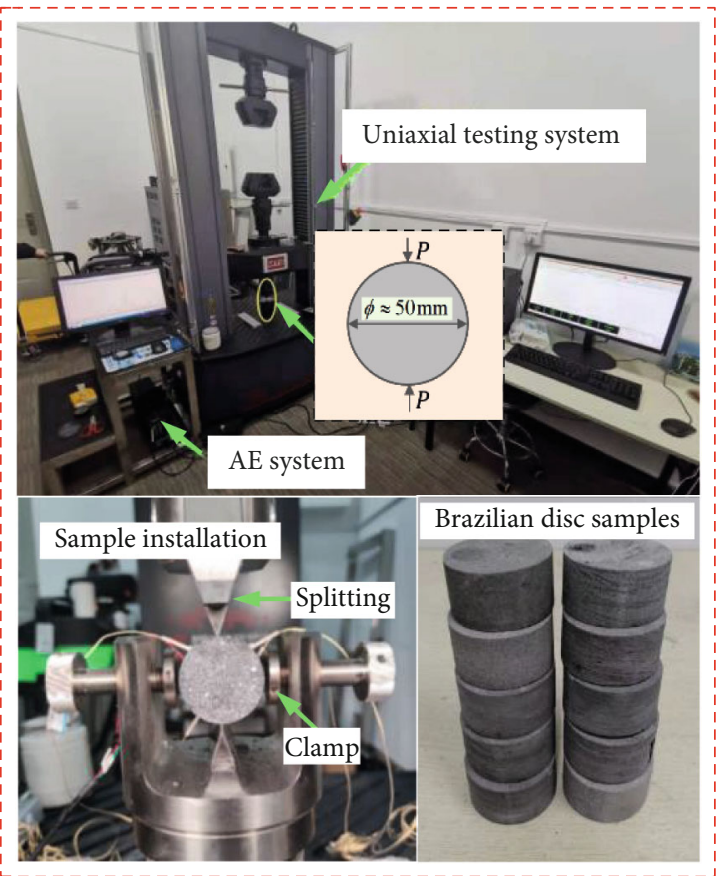

(b) MTS Exceed E45 system

Figure 3: Testing equipment for rock mechanics.

According to the Brazilian test, the ultimate tensile strength $\left(\sigma_{t}\right)$ of rock can be expressed as

$$
\sigma_{t}=\frac{1}{n} \sum_{i=1}^{n} \sigma_{t i}=\frac{1}{n} \sum_{i=1}^{n}\left(\frac{2 P_{i}}{\pi R_{i} t_{i}}\right)
$$

where $\sigma_{t i}$ is the tensile strength of one particular sample; $P_{i}$ means the failure load; $R_{i}$ represents the sample radius; $t_{i}$ is the thickness of the sample; and $n$ denotes the number of tests conducted.

Experimental results show that the tensile strengths at the natural state and fully saturated state are $4.03 \mathrm{MPa}$ and $1.38 \mathrm{MPa}$, respectively. Although the tensile strength drops $66 \%$ when the weakly cemented sandy mudstone is saturated by water, the tensile strength keeps $1 / 10$ of its uniaxial compressive strength at each state.

\subsection{Comparison of Mechanical Properties between Natural} and Fully Saturated Rocks. Based on the aforementioned experiments, the mechanical properties of samples under natural and fully saturated states are shown below in Table 1.

Figure 6 shows the comparison of compressive strength of natural and saturated rock samples under different confining pressures. From Figure 6, one can find that the compressive strength (deviatoric stress) of sandy mudstone increases with the increasing confining pressure, and the enhancing effects of confining pressure on strength are more obvious for water-saturated rocks. For natural sandy mudstone, when the confining pressure increases from $0 \mathrm{MPa}$ to $8 \mathrm{MPa}$, the compressive strength of the rock increases from $35.22 \mathrm{MPa}$ to $63.24 \mathrm{MPa}$ by an increment of $80 \%$. However, the compressive strength of fully saturated sample increases from 15.09 $\mathrm{MPa}$ to $45.17 \mathrm{MPa}$, which is approximately three times. It is found that water saturation has a significant weakening effect on the compressive strength of Buertai sandy mudstone after comparing the natural rock samples with fully saturated rock samples. When the confining pressure increases from $0 \mathrm{MPa}$ to 4,6 , and $8 \mathrm{MPa}$, the compressive strength after water saturation decreases by $57 \%, 45 \%, 38 \%$, and $29 \%$, respectively. Hence, the softening effect of water decreases as the confining pressure increases.

Figure 7 shows the comparison of elastic modulus of natural and fully saturated rock samples under different confining pressures. Table 1 and Figure 7 both show that the elastic modulus of sandy mudstone increases with the increase of confining pressure, and the increasing proportion for both natural and fully saturated rocks is nearly the same. For natural sandy mudstone, when the confining pressure increases from $0 \mathrm{MPa}$ to $8 \mathrm{MPa}$, the elastic modulus increases from $3.81 \mathrm{GPa}$ to $8.28 \mathrm{GPa}$, representing a 1.2 times increment. For saturated sandy mudstone, the elastic modulus increases from $2.75 \mathrm{GPa}$ to $6.18 \mathrm{GPa}$. This is an increase of 1.3 times. Comparing the natural samples with saturated samples, the elastic modulus of saturated samples under different confining pressures is lower than that of the natural state samples under the same confining pressure. The test results also show that the elastic modulus of the rock decreases $25 \% \sim 30 \%$ after being saturated with water.

Figure 8 shows the relationship of Poisson's ratio with confining pressure for natural and saturated rock samples. From the figure, it can be found that the confining pressure has a significant effect on Poisson's ratio. When the rock sample changes from uniaxial compression to triaxial compression, Poisson's ratio decreases significantly. When the confining pressure is small, the water saturation-induced 


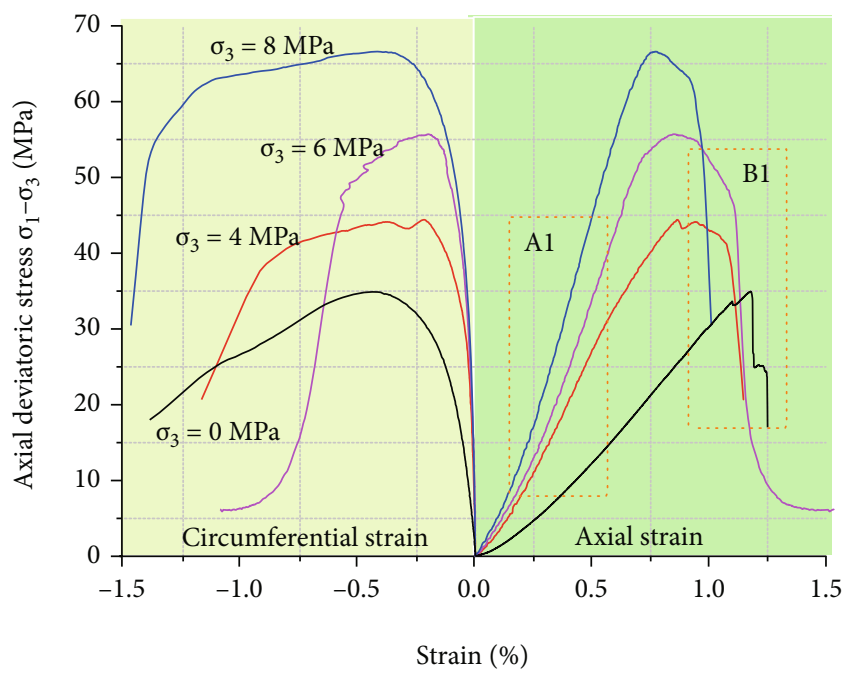

(a) Natural state

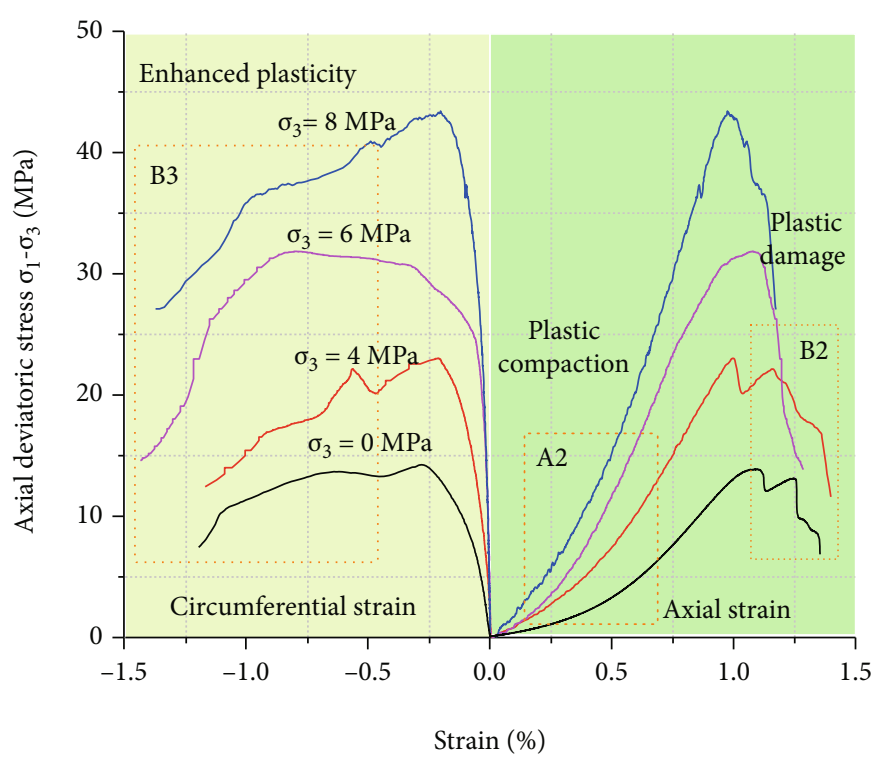

(b) Fully saturated state

FIGURE 4: Relationships between the deviatoric stress and strain for natural and fully saturated rock samples.

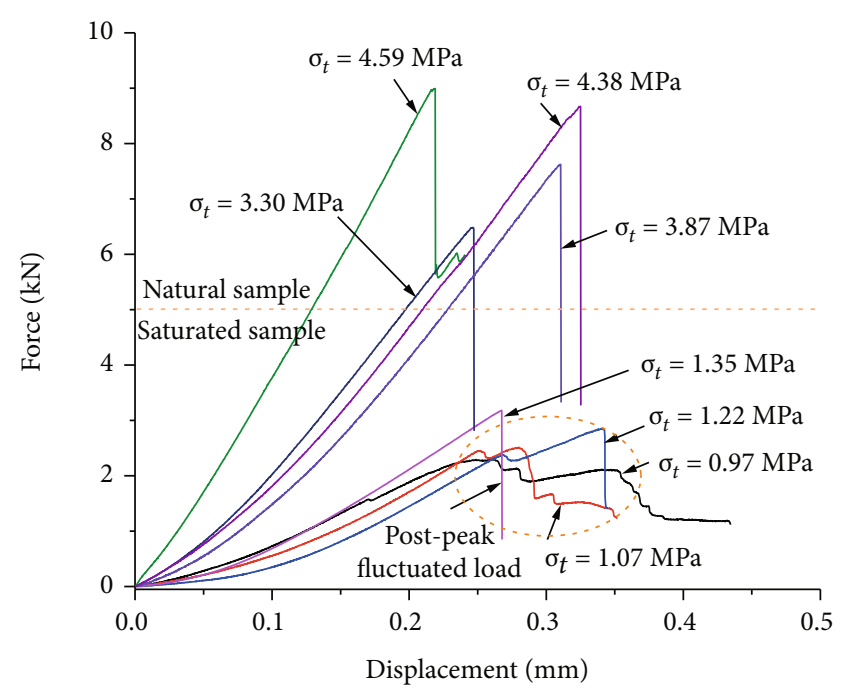

Figure 5: Force-displacement curves of the Brazilian test for natural and fully saturated rock samples.

softening effect on the rock has a significant improvement in the circumferential deformation, resulting in a $16 \%$ larger Poisson ratio in the saturated rock sample than that in the natural state rock sample in uniaxial compression. When the confining pressure is large, the high confining pressure environment has more influence on Poisson's ratio and the difference in Poisson's ratio between the two states of rock becomes negligible.

Figure 9 compares the strain after postpeak strength of natural and saturated rock samples after uniaxial and triaxial compressive failures under different confining pressures. The test results show that the postpeak strain of sandy mudstone in the natural state and saturated state both decreases with the increasing confining pressure. When the confining pressure is $8 \mathrm{MPa}$, the postpeak strain decreases $14 \%$ and
$17 \%$ compared with the uniaxial compression situation, respectively. Under different confining pressures, the postpeak strain of the fully saturated sandy mudstone increases with an average increment of $12 \%$ comparing with the natural state samples. This indicates that the deformability of rock increases after the saturation of water.

Based on the experimental results, the cohesion and internal friction angle of Buertai sandy mudstone under natural and saturated conditions were also calculated. The cohesions of the rock sample in the natural and fully saturated states are $7.32 \mathrm{MPa}$ and $3.24 \mathrm{MPa}$, respectively. The cohesion of the rock after saturation decreases by $56 \%$. Thereby, the change in internal friction of sample in the natural and saturated state is relatively small, which reduces from $41^{\circ}$ to $36^{\circ}$ only.

3.5. Model Modification considering Softening Effect from Water Injection. Based on the theory of elasticoplastic strain, the total strain change of rock can be expressed as

$$
d \varepsilon_{i j}=d \varepsilon_{i j}^{e}+d \varepsilon_{i j}^{p}
$$

where $d \varepsilon_{i j}^{e}$ and $d \varepsilon_{i j}^{p}$ are the increments of the elastic and plastic strain, respectively.

In Equation (2), $d \varepsilon_{i j}^{e}$ can be written as [28]

$$
d \varepsilon_{i j}^{e}=\frac{1}{2 G} d \sigma_{i j}-\frac{\nu}{E} \delta_{i j} d \sigma_{k k}
$$

where $\sigma_{i j}$ means the stress tensor, $G=E / 2(1+v)$ is the shear modulus, $\delta_{i j}$ denotes the Kronecker operator, and $\sigma_{k k}=\sigma_{1}$ $+\sigma_{2}+\sigma_{3}$ is the total principal stress. 
TABLE 1: Mechanical parameters of natural and fully saturated sandy mudstone.

\begin{tabular}{|c|c|c|c|c|c|c|c|}
\hline & $\begin{array}{c}\text { Confining pressure } \\
\sigma_{3}(\mathrm{MPa})\end{array}$ & $\begin{array}{c}\text { Deviatoric stress } \sigma_{1} \\
-\sigma_{3}(\mathrm{MPa})\end{array}$ & $\begin{array}{c}\text { Elasticity } \\
\text { modulus } E(\mathrm{GPa})\end{array}$ & $\begin{array}{l}\text { Poisson's } \\
\text { ratio } v /-\end{array}$ & $\begin{array}{c}\text { Postpeak } \\
\text { strain } \varepsilon_{p}(\%)\end{array}$ & $\begin{array}{c}\text { Cohesion } C \\
(\mathrm{MPa})\end{array}$ & $\begin{array}{c}\text { Internal friction } \\
\text { angle } \varphi\left(^{\circ}\right)\end{array}$ \\
\hline \multirow{4}{*}{$\begin{array}{l}\text { Natural } \\
\text { sample }\end{array}$} & 0 & 35.22 & 3.81 & 0.20 & 1.22 & \multirow{4}{*}{7.32} & \multirow{4}{*}{41} \\
\hline & 4 & 44.07 & 5.19 & 0.18 & 1.17 & & \\
\hline & 6 & 53.80 & 6.76 & 0.16 & 1.10 & & \\
\hline & 8 & 63.24 & 8.28 & 0.17 & 1.05 & & \\
\hline \multirow{4}{*}{$\begin{array}{l}\text { Saturated } \\
\text { sample }\end{array}$} & 0 & 15.09 & 2.75 & 0.26 & 1.41 & \multirow{4}{*}{3.24} & \multirow{4}{*}{36} \\
\hline & 4 & 24.12 & 3.58 & 0.20 & 1.37 & & \\
\hline & 6 & 33.47 & 4.94 & 0.17 & 1.23 & & \\
\hline & 8 & 45.17 & 6.18 & 0.16 & 1.17 & & \\
\hline
\end{tabular}

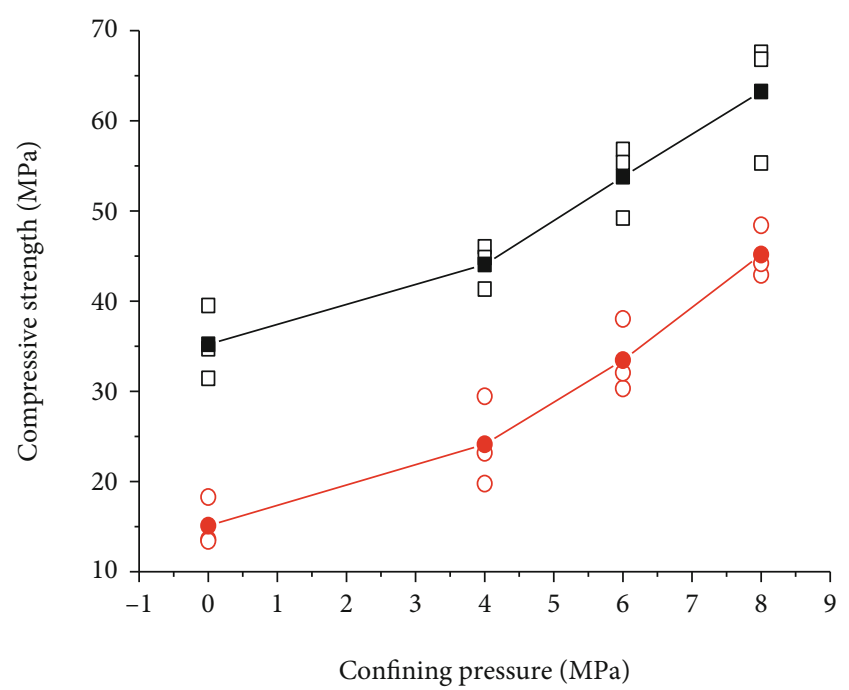

$\square$ Natural sample, test $\quad-$ - Natural sample, mean

○ Saturated sample, test $\quad-\bullet-$ Saturated sample, mean

FIGURE 6: The relationship between compressive strength and confining pressure of natural and fully saturated rock samples.

Besides, $d \varepsilon_{i j}^{p}$ can be expressed as [29]

$$
\left\{\begin{array}{l}
d \varepsilon_{i j}^{p}=d \gamma \cdot \frac{\partial g}{\partial \sigma_{i j}}, \\
g=\sigma_{1}-\frac{1+\sin \varphi}{1-\sin \varphi} \sigma_{3},
\end{array}\right.
$$

in which $\gamma$ represents the plastic factor, $\varphi$ is the internal friction angle, and $g$ is the plastic function.

Considering the water softening effect and the pore pressure effect on effective stress, $d \varepsilon_{i j}^{e}$ can be modified as

$\left\{\begin{array}{l}d \sigma_{i j}^{e}=2 \varepsilon_{i j}^{e} \cdot d G(\theta)+2 G(\theta) \cdot d \varepsilon_{i j}^{e}+\delta_{i j} \varepsilon_{k k} \cdot d M(\theta)+M(\theta) \delta_{i j} \cdot d \varepsilon_{k k}-\alpha \delta_{i j} \cdot d p, \\ M=2 G(\theta) v(\theta) /[1-2 v(\theta)],\end{array}\right.$

where $p$ is pore pressure in the fractures and $\alpha$ means the Biot coefficient, whereas $d \varepsilon_{i j}^{p}$ can be modified as

$$
\left\{\begin{array}{l}
d \varepsilon_{i j}^{p}=d \gamma(\theta) \cdot \frac{\partial g}{\partial\left(\sigma_{i j}-\alpha p\right)}, \\
g=\sigma_{1}(\theta)-\frac{1+\sin \varphi(\theta)}{1-\sin \varphi(\theta)} \sigma_{3}(\theta) .
\end{array}\right.
$$

Equations (3), (5), and (6) form the modified constitutive model by considering the softening effect of water saturation on rock.

3.6. Discussion on Constitutive Model of Sandy Mudstone. Water has a significant softening effect on sandy mudstone. However, previous studies on rock deformation and water seepage problems in mine engineering mostly neglected the modification of the constitutive models. The abovementioned modified method for the constitutive model considering the softening effect of water injection into rock mass provides a simplified solution. The constitutive model in Equation (6) can be validated and simplified by certain tests and subsequently used in the development of numerical program in rock engineering.

Take the background of the samples in this work from the roof of Buertai mine, Shendong coal mining area, as an example, the sandy mudstone is in an elastic compression state in the in situ stress field. From the test results in Section 3.4 , it can be seen that the changes in Poisson's ratio and internal friction angle of the rock before and after water softening under a certain confining pressure (depth) are minimal enough to be ignored. The elastic modulus decreases by about $30 \%$ under different confining pressures. By substituting these conclusions into Equation (6), one obtains

$$
\begin{aligned}
d \sigma_{i j}^{e}= & \frac{v}{1+v}\left(\frac{1}{v} \varepsilon_{i j}^{e}+\frac{1}{1-2 v} \delta_{i j} \varepsilon_{k k}\right) \cdot d E(\theta)+\frac{E(\theta)}{1+v} d \varepsilon_{i j}^{e} \\
& +\frac{v}{1+v} \frac{E(\theta)}{1-2 v} \delta_{i j} \cdot d \varepsilon_{k k}-\alpha \delta_{i j} \cdot d p
\end{aligned}
$$

Furthermore, by implementing more experiments to obtain $E(\theta), v$, and $\alpha$, Equation (7) can be further simplified. Alternatively, numerical solution can be gathered by using existing numerical software, which will not be described here. 


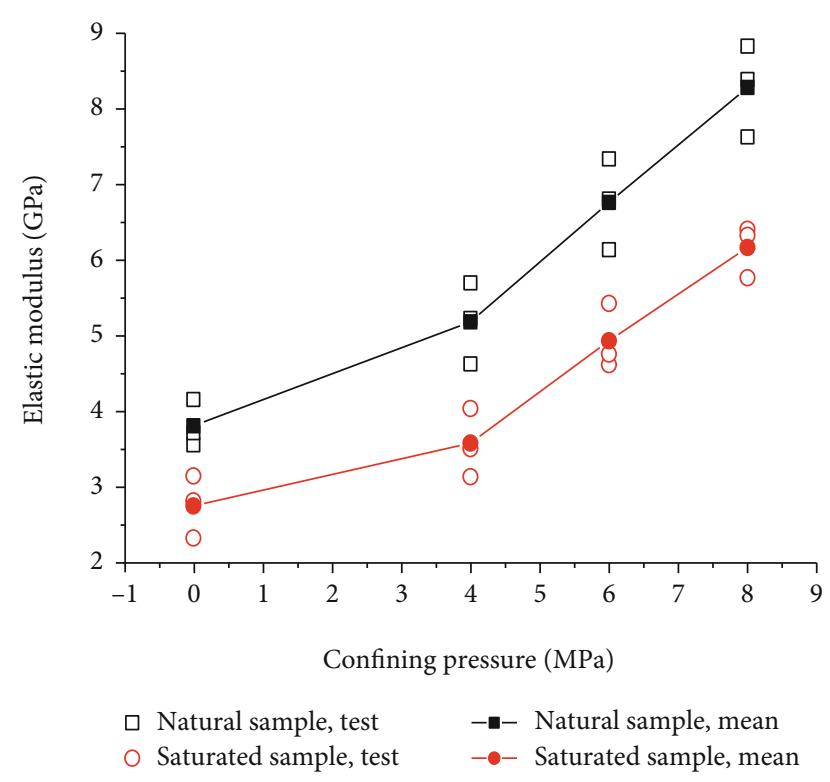

FIGURE 7: The relationship between elastic modulus and confining pressure of natural and fully saturated rock samples.

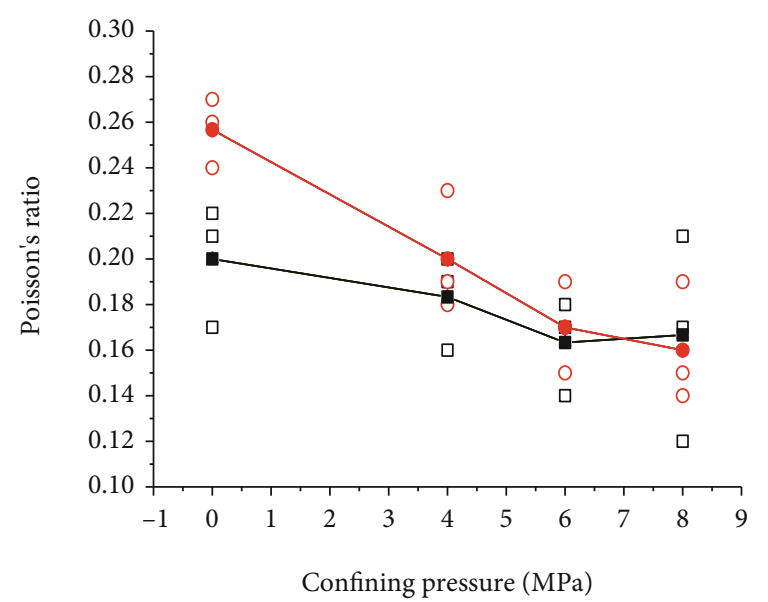

口 Natural sample, test $\quad-\square-$ Natural sample, mean

- Saturated sample, test - $\bullet-$ Saturated sample, mean

FIgURE 8: The relationship between Poisson's ratio and confining pressure of natural and water-saturated rock samples.

\section{Couplings among Stress-Damage-Seepage and Permeability Model}

4.1. Experimental Design and Procedures. For the fully saturated sandy mudstone samples, a full-process permeability test during the triaxial compression was carried out to study the coupled stress-deformation-seepage interactions. The confining pressure was applied to the rock sample at a loading rate of $1 \mathrm{MPa} / \mathrm{min}$ to a specified target of $3 \mathrm{MPa}$ and kept constant. This confining pressure corresponds to a depth of about $400 \mathrm{~m}$. The axial pressure was applied by displacement control and stress servo loading method. The displacement rate was $0.02 \mathrm{~mm} / \mathrm{min}$. The water pressure at the inlet of the rock sample was controlled at $1.1 \mathrm{MPa}$, and the outlet was connected to the atmosphere. After the seepage was sta-

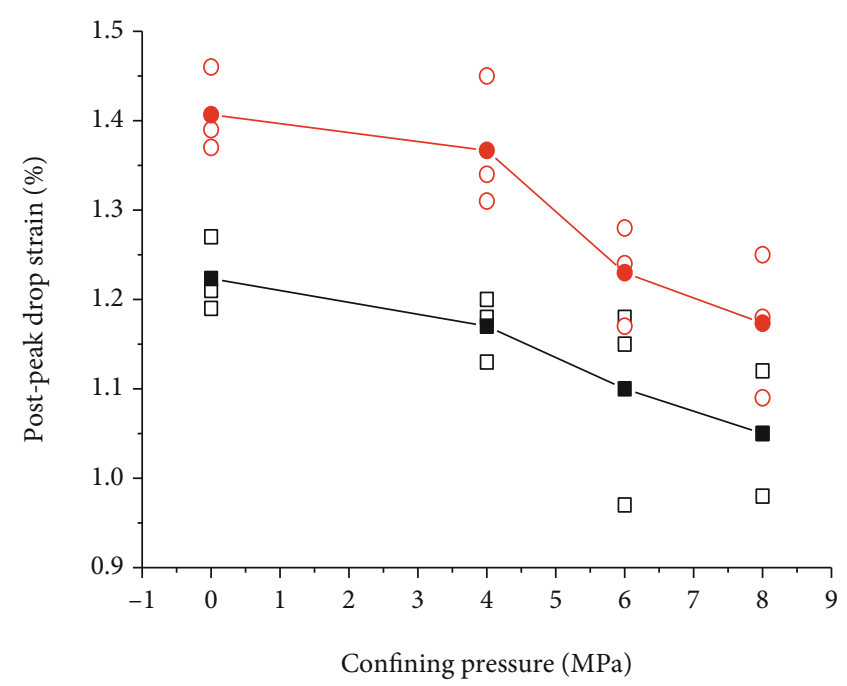

$\begin{array}{ll}\square \text { Natural sample, test } & -\square-\text { Natural sample, mean } \\ \circ \text { Saturated sample, test } & -0-\text { Saturated sample, mean }\end{array}$

FIgURe 9: Postpeak strain of natural and saturated rock samples under different confining pressures.

bilized, the rock sample was tested for axial deformation and flow velocity under triaxial compression. The test was repeated twice under each axial pressure with a time interval of not less than $1 \mathrm{~min}$. After the test under one axial pressure was completed, the axial pressure was increased by 2-3 MPa. The measurement was performed again until the rock sample was completely failed. In the experiments, Darcy's law is used to evaluate the seepage behavior $[8,30]$.

4.2. Analysis on Stress-Seepage Couplings. Figure 10 shows the coevolution relationship of stress-strain and permeability of sandy mudstone in the complete triaxial compression. It is clear that the permeability process of sandy mudstone under the triaxial loading can be divided into three stages. The first stage is the seepage shielding stage. At this stage, the permeability of the rock decreases with the increase of the stress level, from the initial value of $0.056 \mathrm{mD}$ to $0.014 \mathrm{mD}$. The reason is that the effective stress closes the preexisting fractures in the samples. By comparing the stress-strain curve with the seepage evolution curve, it can be found that the seepage shielding stage corresponds to the prepeak compaction, elastic, and initial plastic damage stages. The second stage is the seepage surge stage. As the rock sample is compressed and failed, the original fractures in the rock sample further develop and join together accompanied by newly formed fractures. The permeability increases significantly from $0.014 \mathrm{mD}$ to $0.27 \mathrm{mD}$, and this is 3.8 times of its initial permeability. The seepage surge stage corresponds to the late plastic damage stage and failure stage of the rock sample under triaxial compression. The third stage is the seepage recovery stage. The permeability of the rock sample decreases and recovers with postpeak deformation. The fully saturated sandy mudstone has weak cementation from the previous rock hydraulic effects. It can be seen from Figure 10 that obvious rheological behavior 


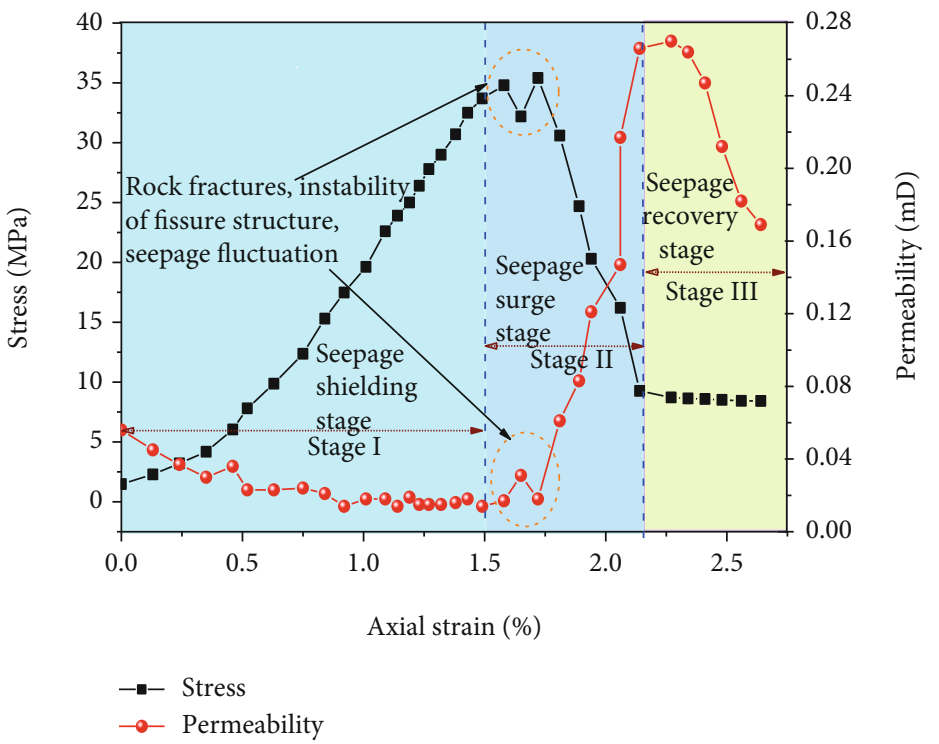

Figure 10: Coevolution curves of stress-strain and permeability in sandy mudstone triaxial tests.

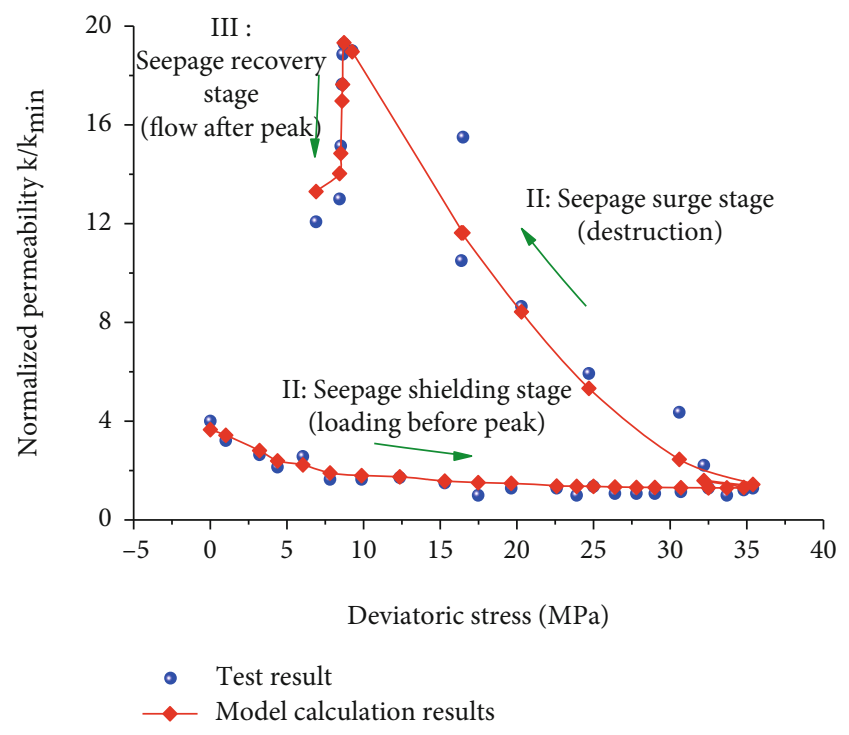

FIGURE 11: Verification of permeability model in the complete process of rock compression.

appears after rock failure. It results in water filling in fractures, dislocation, or further compaction, which ultimately leads to a decrease in permeability. The seepage recovery stage corresponds to the postpeak rheological stage in the triaxial test. The reality is obvious that the permeability of rock in the late stage III could not keep dropping at a high rate, and the permeability will become stable with the increase of deformation after failure. In Figure 10, the seepage rate of the late stage III gradually decreases. In this test, the postpeak permeability test data is limited and the process is not fully captured.

4.3. A Coupled Stress-Damage-Permeability Model on Sandy Mudstone. Assuming the opening width of the fracture is $b$, the mean tortuosity is $\tau$, the crack length per unit area is $L$, and the fracturing area per unit volume is $S$; the permeability [31] and porosity for fractured rock in layers can be estimated as

$$
\begin{aligned}
& k=\frac{L}{12 \tau} b^{3}, \\
& \phi=b S .
\end{aligned}
$$

By substituting Equation (9) into Equation (8), one obtains

$$
k=\frac{L}{12 \tau S^{3}} \phi^{3} .
$$

The partial derivative of the permeability to the effective stress in Equation (10) can be expressed as

$$
\begin{aligned}
\frac{\partial k}{\partial \sigma_{e}} & =\frac{L \phi^{2}}{4 \tau S^{3}} \frac{\partial \phi}{\partial \sigma_{e}}=3 D_{f} k \\
D_{f} & =\frac{1}{\phi} \frac{\partial \phi}{\partial \sigma_{e}}
\end{aligned}
$$

where $D_{f}$ means the effective stress effect on porosity, which is proportional to rock damage, i.e., $D_{f}=\lambda_{f} D$. $\lambda_{f}$ is the coefficient of fracture development on effective stress, which can be represented by $\lambda_{f}=-\lambda_{k} c_{f}$ in which $\lambda_{k}$ denotes the coefficient of damage on permeability.

By substituting rock damage and compression coefficients into Equation (11), one finds that

$$
\frac{\partial k}{\partial \sigma_{e}}=-3 \lambda_{k} c_{f} D k .
$$


TABLE 2: Parameters for permeability model validation.

\begin{tabular}{lcccccc}
\hline Parameter & $\theta$ & $E_{0}(\theta)$ & $\sigma_{e 0}$ & $k_{\min }$ & $\lambda_{f}$ & $R^{2}$ \\
\hline Magnitude & 5.9 & 2.27 & 0 & 0.014 & 0.316 & $\mathrm{MPa}^{-1}$ \\
Unit & $\%$ & $\mathrm{GPa}$ & $\mathrm{MPa}$ & $\mathrm{mD}$ & - \\
Source & Experiment & Experiment & Experiment & Experiment & Regression & Regression \\
\hline
\end{tabular}

By integrating Equation (12), one gets

$$
k=k_{0} e^{-3 \lambda_{k} c_{f} D\left(\sigma_{e}-\sigma_{e 0}\right)},
$$

where 0 means the initial values.

Equation (13) shows a permeability model for rock mass based on the evolution of stress and damage. It can be seen that the rock permeability has an inverse exponential relationship with the effective stress. In particular, it should be noted that the damage of rock can be further defined according to specific observation methods, such as the using of extensive elastic modulus degradation, i.e., $D=1-E / E_{0}$. Besides, when considering changes of the conditions of the rock, the basic mechanical properties in the model are no longer constants. For example, considering the softening effect caused by water injection in weakly cemented sandy mudstone, the permeability model can be expressed as

$$
k / k_{0}=e^{-3 \lambda_{k}(\theta) c_{f}(\theta)\left[1-E(\theta) / E_{0}\right]\left(\sigma_{e}-\sigma_{e 0}\right)},
$$

in which $\theta$ means the water content and $\sigma_{e}$ denotes the effect of pore pressure.

4.4. Model Validation. The permeability model proposed in this study is to validate by the sandy mudstone data and permeability test results. Figure 11 shows the verification results of the coupled stress-damage-permeability model with the model verification parameters in Table 2 . It can be seen that the experimental results are in line with the model calculation result.

\section{Conclusion}

In this paper, the hydraulic effect and seepage behavior of weakly cemented sandy mudstone in the Buertai coal mine of Shendong mining area were systematically studied. Based on the experimental results, a modified constitutive model considering softening effect of water injection and a stressdamage-driven model for permeability evolution were proposed to incorporate stress-damage-seepage couplings. The following conclusions can be drawn:

(1) Water softening on weakly cemented sandy mudstone is significant. After water saturation, the plasticity increases, and the compressive strength decreases by $29 \% \sim 57 \%$. Thereby, the smaller the confining pressure, the higher the softening effect on compressive strength. The modulus of elasticity decreases by $25 \% \sim 30 \%$. Although the modulus of elasticity increases with the increasing confining pressure, the incremental ratio for natural and satu- rated rocks under compression was similar. Changes in Poisson's ratio are relatively weak that can be ignored under both high and low confining pressures. The postpeak dropped strain decreases with the increase of the confining pressure, but it increases $12 \%$ after water saturation under any confining pressure. Besides, the cohesion decreases by $56 \%$ and the internal friction angle decreases by $12 \%$. The ultimate tensile strength decreases by $66 \%$

(2) The evolution of rock permeability of weakly cemented sandy mudstone during triaxial compression is corresponding to rock complete compressional deformation that can be divided into seepage shielding, seepage surge, and seepage recovery stages. The permeability at each stage has a negative exponential relationship with effective stress

The research results can effectively enrich the fundamental theory of rock mechanics and provide guidance for the engineering practices of hard roof pressure relief, underground reservoir construction, and the prevention of mine water disaster.

\section{Data Availability}

The data appearing in the manuscript is available by contacting the corresponding author after the publication of the manuscript.

\section{Disclosure}

This paper has been published as a preprint at the following link: https://www.researchsquare.com/article/rs-944637/v1.

\section{Conflicts of Interest}

There are no conflicts of interest to declare.

\section{Authors' Contributions}

TT and JG were responsible for writing original draft and data processing. XZ was responsible for methodology, review, and editing. YW was responsible for review and editing. ZL was responsible for data processing. YT was responsible for revising the work. All the authors of this manuscript have approved the article's submission for publication.

\section{Acknowledgments}

This paper is supported by the National Natural Science Foundation (52004285), the Open Fund of State Key 
Laboratory of Water Resource Protection and Utilization in Coal Mining (GJNY-18-73-16, GJNY-20-113-20), the Open Fund of State Key Laboratory of Mining Response and Disaster Prevention and Control in Deep Coal Mine (SKLMRDPC19KF06), and the Open Fund of State Key Laboratory for GeoMechanics and Deep Underground Engineering (SKLGDUEK2123).

\section{References}

[1] D. Z. Gu, "Theory framework and technological system of coal mine underground reservoir," Journal of China Coal Society, vol. 40, no. 2, pp. 239-246, 2015.

[2] A. P. Jarvis, J. E. Davis, P. H. Orme, H. A. Potter, and C. J. Gandy, "Predicting the benefits of mine water treatment under varying hydrological conditions using a synoptic mass balance approach," Environmental Science \& Technology, vol. 53, no. 2, pp. 702-709, 2018.

[3] H. Song, J. Xu, J. Fang, Z. Cao, Y. Li, and T. Li, "Potential for mine water disposal in coal seam goaf: investigation of storage coefficients in the Shendong mining area," Journal of Cleaner Production, vol. 244, 2019.

[4] F. Du and S. S. Peng, "Change rule of physical and mechanical property of rock mass in Shendong mine," Journal of Mining \& Safety Engineering, vol. 36, no. 5, pp. 1009-1015, 2019.

[5] J. Guo, T. Teng, X. Zhu, Y. Wang, and Z. Li, "Characterization and modeling study on softening and seepage behavior of weakly cemented sandy mudstone after water injection," 2021, https://www.researchsquare.com/article/rs$944637 / \mathrm{v} 1$

[6] H. Li, H. Li, G. Song, and K. Wang, "Physical and mechanical properties of the coal-bearing strata rock in Shendong coal field," Journal of China Coal Society, vol. 41, no. 11, pp. 2661-2671, 2016.

[7] J. Z. Yang, K. G. Zheng, Z. R. Wang, and N. Y. Pang, “Technology of weakening and danger-breaking dynamic disasters by hard roof," Journal of China Coal Society, vol. 45, no. 10, pp. 3371-3379, 2020.

[8] O. O. Selene, E. Oscar, M. Jurgen et al., "Water-rock interaction and mixing processes of complex urban groundwater flow system subject to intensive exploitation: the case of Mexico City," Journal of South American Earth Sciences, vol. 103, 2020.

[9] S. Goodarzia, J. Hassanpour, S. Yagiz, and J. Rostamic, "Predicting TBM performance in soft sedimentary rocks, case study of Zagros mountains water tunnel projects," Tunnelling and Underground Space Technology, vol. 109, 2021.

[10] M. M. Kou, X. R. Liu, Z. Q. Wang, and M. Nowruzpour, "Mechanical properties, failure behaviors and permeability evolutions of fissured rock-like materials under coupled hydro-mechanical unloading," Engineering Fracture Mechanics, vol. 254, article 107959, p. 107929, 2021.

[11] M. Sawatsubashi, K. Takashi, and K. Toshihiko, "Effect of initial water content and shear stress on immersion-induced creep deformation and strength characteristics of gravelly mudstone," Soils and Foundations, vol. 61, no. 5, pp. 12231234, 2021.

[12] Q. L. Yao, F. T. Zhang, X. L. Ding, L. Zhang, and G. Jiang, "Experimental research on instability mechanism of silty mudstone roofs under action of water and its application," Procedia Earth and Planetary Science, vol. 1, no. 1, pp. 402-408, 2009.
[13] Y. Luo, "Influence of water on mechanical behavior of surrounding rock in hard-rock tunnels: an experimental simulation," Engineering Geology, vol. 277, 2020.

[14] W. Liu, E. Yan, H. Dai, Y. Du, W. B. Xiao, and S. Zhao, "Study on characteristic strength and energy evolution law of Badong formation mudstone under water effect," Chinese Journal of Rock Mechanics and Engineering, vol. 39, no. 2, pp. 311-326, 2020.

[15] P. Hou, X. Liang, F. Gao, J. B. Dong, J. He, and Y. Xue, "Quantitative visualization and characteristics of gas flow in 3D porefracture system of tight rock based on lattice Boltzmann simulation," Journal of Natural Gas Science and Engineering, vol. 89, p. 103867, 2021.

[16] P. Hou, X. Liang, Y. Zhang, J. He, F. Gao, and J. Liu, “3D multiscale reconstruction of fractured shale and influence of fracture morphology on shale gas flow," Natural Resources Research, vol. 30, no. 3, pp. 2463-2481, 2021.

[17] T. Teng, F. Gao, Y. Ju, and Y. Xue, "How moisture loss affects coal porosity and permeability during gas recovery in wet reservoirs?," International Journal of Mining Science and Technology, vol. 27, no. 6, pp. 899-906, 2017.

[18] S. Song, B. Qin, H. Xin, and K. Chen, "Exploring effect of water immersion on the structure and low-temperature oxidation of coal: a case study of Shendong long flame coal, China," Fuel, vol. 234, pp. 732-737, 2018.

[19] S. Ali and Z. Davood, "Detailed analysis of the brine-rock interactions during low salinity water injection by a coupled geochemical-transport model," Chemical Geology, vol. 537, no. 30, article 119484, 2020.

[20] Z. Wen, P. F. Jiang, S. L. Jing, and Z. G. Cao, "Development and verification of simulation testing system for floor seepage in coal mine underground reservoir," Journal of China Coal Society, vol. 46, no. 5, pp. 1487-1497, 2021.

[21] J. C. Robert, F. H. Jon, S. Shanvas, N. Simon, and T. Jean, "The role of the stress-path and importance of stress history on the flow of water along fractures and faults; an experimental study conducted on kaolinite gouge and CallovoOxfordian mudstone," Applied Clay Science, vol. 150, pp. 282-292, 2017.

[22] T. Wu, X. F. Fu, B. Liu, H. X. Wang, Z. H. Xie, and Z.-J. Pan, "Mechanical behavior and damage-induced permeability evolution of mudstone and gypsum caprocks," Journal of Petroleum Science and Engineering, vol. 196, 2021.

[23] S. Uehara and M. Takahashib, "Evolution of permeability and microstructure of experimentally-created shear zones in Neogene siliceous mudstones from Horonobe, Japan," Journal of Structural Geology, vol. 60, pp. 46-54, 2014.

[24] N. Mohammad, H. M. Nazmul, and H. Helge, "Permeability and physical properties of semi-compacted fine-grained sediments - a laboratory study to constrain mudstone compaction trends," Marine and Petroleum Geology, vol. 102, pp. 590-603, 2019.

[25] A. Ahmet and H. Ç. Ismail, "Investigation of the density, porosity, and permeability properties of pervious concrete with different methods," Construction and Building Materials, vol. 294, 2021.

[26] B. Sibiryakovb, L. W. B. Leitea, and E. Sibiriakov, "Porosity, specific surface area and permeability in porous media," Journal of Applied Geophysics, vol. 186, 2021.

[27] T. Teng, J. Wang, F. Gao, Y. Ju, and T. Xia, "Impact of water film evaporation on gas transport property in fractured wet 
coal seams," Transport in Porous Media, vol. 113, no. 2, pp. 357-382, 2016.

[28] T. Teng, Y. Zhao, F. Gao, J. G. Wang, and W. Wang, "A fully coupled thermo-hydro-mechanical model for heat and gas transfer in thermal stimulation enhanced coal seam gas recovery," International Journal of Heat and Mass Transfer, vol. 125, pp. 866-875, 2018.

[29] Y. N. Wang, Q. Zhang, Z. Y. Li, and B. S. Jiang, "Strain softening model considering elastic-plastic coupling effect," Journal of China Coal Society, vol. 45, no. 12, pp. 4037-4051, 2020.

[30] Y. Xue, J. Liu, P. G. Ranjith, X. Liang, and S. Wang, "Investigation of the influence of gas fracturing on fracturing characteristics of coal mass and gas extraction efficiency based on a multi-physical field model," Journal of Petroleum Science and Engineering, vol. 206, 2021.

[31] Y. Xue, F. Gao, and X. Liu, "Effect of damage evolution of coal on permeability variation and analysis of gas outburst hazard with coal mining," Natural Hazards, vol. 79, no. 2, pp. 9991013, 2015. 